\title{
Intravenous Solutions for Exploration Missions
}

\author{
Fletcher J. Miller* \\ National Center for Space Exploration Research, Cleveland, OH, 44135-3191, USA \\ Charles Niederhaus ${ }^{\dagger}$, Karen Barlow ${ }^{\ddagger}$, and DeVon Griffin ${ }^{\S}$ \\ NASA Glenn Research Center, Cleveland, OH, 44135-3191, USA
}

\begin{abstract}
This paper describes the intravenous (IV) fluids requirements being developed for medical care during NASA's future exploration class missions. Previous research on IV solution generation and mixing in space is summarized. The current exploration baseline mission profiles are introduced, potential medical conditions described and evaluated for fluidic needs, and operational issues assessed. We briefly introduce potential methods for generating IV fluids in microgravity. Conclusions on the recommended fluid volume requirements are presented.
\end{abstract}

\section{Introduction}

The Vision for Space Exploration outlined a new direction for NASA, consisting of missions unlike those accomplished before. These missions will return astronauts to the Moon and test the technologies required for Mars missions. The International Space Station (ISS) will be used as a test bed for some of these new technologies. NASA's Exploration Systems Architecture Study presents the Design Reference Missions (DRMs) that are being used to facilitate the derivation of requirements for the essential technologies. These DRMs include missions to ISS, Lunar Sorties, Lunar Outposts, and Mars Exploration. ${ }^{1}$

These longer duration missions increase the likelihood of a medical incident and thus the need for medical fluids. The Patient Condition DataBase (PCDB) contains a list of over 400 medical conditions that may present and require treatment during ISS missions. ${ }^{2}$ These conditions are a subset of the total possible conditions that could be encountered during long duration, Extra-Vehicular Activity (EVA) intensive, exploration missions. Of the 442 conditions, approximately 115 may require medical fluids during the course of treatment. Terrestrial treatment would typically include fluids such as Normal Saline (NS) $(0.9 \% \mathrm{NaCl}), 5 \%$ Dextrose, Lactated Ringer's, or whole blood. Operational constraints, such as mass limitations and lack of refrigeration, may limit the type and volume of such fluids that can be carried onboard the spacecraft. Representative conditions that would require fluid treatment include major bone fracture, burns, and acute anemia. These conditions are described in detail later in this paper.

Choosing a technology to generate sterile water for injection and produce intravenous fluids requires balancing capabilities with mission and medical requirements. For example, the type, volume, and timeline over which IV fluids are required are key drivers in selecting an appropriate technology. Additionally, the system must operate in various gravity environments, such as microgravity, lunar gravity, and Martian gravity, while also functioning in earth normal gravity for testing and verification. Thrusting events also produce an effective gravitational level and could possibly occur during fluid production. Successful operation requires maintaining sterility. Some technologies might be sealed until use, requiring only seal integrity, while other systems may require internal recirculation or periodic maintenance to ensure proper operation. Diagnostics will likely be required to verify proper operation of the system. Crew time is always an issue, and may be especially important in an emergency. Any system must be relatively simple to use, safe, and reliable.

\footnotetext{
* Principal Researcher, MS 110-3

${ }^{\dagger}$ Aerospace Engineer, System Engineering, MS 86-12, Full AIAA Member

\# Student Trainee (Engineering), Bioscience and Technology Branch, MS 77-5,

${ }^{\S}$ Physical Scientist, Human Research Office, MS 77-5
} 


\section{A. Previous Research}

In the late 1980s and early 1990s, NASA conducted a detailed investigation to determine the possibility of producing IV fluids on orbit as part of the Health Maintenance Facility of the Space Station Freedom Program. The Johnson Space Center (JSC) led this effort, which included contracts with Krug International, Sterimatics, and Baxter, culminating in a flight experiment on STS-47 from 9/12/1992 - 9/20/1992. The final decision at the time was not to produce sterile water on Space Station Freedom, but to use prepackaged IV fluids. No flight-ready hardware was fabricated for sterile water production. This section briefly summarizes the results of those earlier efforts.

\section{IV Fluids Requirements White Paper}

Creager of Krug Life Sciences (1991) evaluated six scenarios requiring fluids for medical treatment. ${ }^{3}$ Fluid volumes were calculated for each scenario using seven types of solutions. The volume required to cover a particular scenario ranged from $11 \mathrm{~L}$ to $90 \mathrm{~L}$, averaging $37 \mathrm{~L}$. The total volume required to treat all individual scenarios envisioned for a mission and the minimum volume required to any one individual scenario in a mission were also calculated. The total volume of the 7 types of solutions required to cover one incident of each scenario was $220 \mathrm{~L}$, while $141 \mathrm{~L}$ was the maximum required to cover any single scenario. (The report suggested that the minimum was $123 \mathrm{~L}$ but there was an $18 \mathrm{~L}$ error in the calculations for the minimum amount of Normal Saline required.)

\section{Sterile Water for Injection System}

Krug International, as lead contractor for the Health Maintenance Facility on Space Station Freedom, contracted with Sterimatics Corporation to develop a Sterile Water for Injection System (SWIS) as part of a system to produce IV fluids. The SWIS was a filter/adsorption based technology to produce Water for Injection (WFI). The design goal was to convert ISS "hygiene water," which has a lower quality than potable water, to produce WFI. System requirements included producing at least $6 \mathrm{~L}$ of WFI at $6 \mathrm{~L} / \mathrm{hr}$ with a sterile shelf life of 90 days, utilizing a filter with a minimum shelf life of 1 year. As developed, the SWIS had a dry mass of $2 \mathrm{~kg}$ and produced $9 \mathrm{~L}$ of WFI from water containing contamination levels 10 times the ISS potable water specification. Testing indicated that at least $20 \mathrm{~L}$ of WFI could be produced from potable water. The SWIS was flown on STS-47 in September 1992 as part of the Fluid Therapy System on the Spacelab-J (Spacelab-Japan).

\section{Zero Gravity IV Mixing System}

Krug International contracted with Baxter Healthcare to produce a system for mixing constituents in custom IV bags. Baxter worked on developing methods to mix both powders and concentrates, but was unable to overcome problems in mixing powders. ${ }^{4}$ The development was constrained by a passive system requirement, utilizing only water pressure to produce the mixing. Baxter conducted experiments with a dyed concentrate and observed a low degree of mixing, with the heavier, dyed concentrate located on the bottom of the bag in $1 \mathrm{~g}$ testing. No quantitative mixing studies were completed in normal or microgravity. Subsequent analysis and tests have demonstrated that these mixing techniques can easily be gravity-driven and care must be taken not to interpret those results as a testament to their effectiveness in microgravity. ${ }^{4}$

\section{STS-47 Fluid Therapy System}

The Spacelab-Japan Module flew on STS-47 during September 1992. One of the experiments was the Fluid Therapy System (FTS), testing the equipment and procedures developed thus far for IV generation. The FTS utilized the adsorption filters developed by Sterimatics to produce the WFI, and the IV bags and mixing method developed by Baxter to produce the final solutions. An infusion pump administered a saline solution into a mannequin arm to complete an end-to-end system test. The degree of mixing was not quantified on orbit, nor was the solution frozen or fixed in any fashion to preserve the state of mixing on orbit. While later analysis on Earth showed that the final solution met the tolerance criteria for solution concentration ( $\pm 5 \%$ of desired concentration), that determination was only a validation of the amount of solute in the final solution, not a verification of achieving the in-flight mixing requirements because vibrations from landing and handling as well as molecular diffusion would have easily homogenized the sample by the time the post-flight analysis was performed. Ground testing of the produced WFI also concluded that it exceeded the maximum Total Organic Carbon requirement. It has been speculated that the source of this carbon was from the IV bags themselves, although channeling in the adsorption system is also possible. In addition, Astronaut Mae Jemison observed serious bubble problems during the experiment.

\section{B. Objectives of this Paper}

This paper focuses on describing the requirements for IV fluids for NASA's missions and presenting key issues in developing any IV generation system. It introduces potential generation technologies, and presents conclusions on whether generating IV fluids on orbit is preferable to flying pre-packaged supplies. The profiles of expected missions, as outlined in the Exploration Systems Architecture Study (ESAS) Design Reference Missions (DRM), are 
described and analyzed for potential emergency medical care needs. These missions are still very early in the planning stages, so detailed equipment requirements have not been developed, and mission scenarios may change. Much of the expected medical care needs are based on current and past mission requirements, as well as past advanced planning.

Potential medical conditions are analyzed to determine whether IV fluids might be required and the approximate quantity. The analysis is on a layman's level to give a rough estimate of fluids requirements. Some of the key questions and requirements that an IV generation system must meet are elucidated. Questions include quantities required, production rate requirements, quality requirements, and in-space operation. Some potential technologies are summarized. Conclusions are drawn about whether produced or stored IV fluids are more appropriate for a given DRM.

\section{Medical Conditions Requiring Fluid Treatment}

The ISS PCDB was analyzed to determine which potential conditions require fluid treatment. ${ }^{2}$ Of the 442 listed patient conditions that may be encountered while onboard the ISS, approximately 115 may require intravenous fluid treatment. These conditions may also occur on other exploration missions, possibly with a different probability of occurrence. These possible conditions have been grouped into major areas where the reason for fluid treatment is approximately the same. The required treatment is developed only at the top level, following standard medical practices. Individual patient situations and physician preference may change the preferred fluid treatment.

From the point of view of providing WFI for exploration missions, the most demanding scenario is treating a 100 $\mathrm{kg}$ male. While NASA does not have official astronaut weight standards, the maximum height allowed is 76 in, and the maximum Air Force pilot weight at 76 in height is $102 \mathrm{~kg}$. The main goal in this study is to determine the overall volume of fluids required, and which solutions are generally preferred. These results will be used to define and size an IV fluid generation system. The Space Medicine Division will determine actual fluid requirements for an operational system.

\section{A. Severe Burn}

Serious burns increase capillary permeability, causing fluid to shift from the vascular system into the surrounding interstitial space. This shift occurs in thermal burns of 2nd and 3rd degree, as well as severe chemical and radiation burns. Fluid treatment is based on the size of the burned surface area, and is the same for all types of burns. Burn surface area calculations include areas with 2nd and 3rd degree burns, but not 1st degree burns. Burns covering more than 15\% Total Body Surface Area (TBSA) require fluid treatment to replace the lost intravascular volume. In these cases, prompt fluid treatment is critical to survival. There are many guidelines for fluid treatment, but the most widely recognized is the Parkland formula ${ }^{6}$. Most guidelines recommend fluid treatment for $24 \mathrm{hrs,} \mathrm{and}$ then lesser treatment for the next 24-48 hours, with fluid intake levels approaching normal maintenance requirements.

For this paper, the recommendations contained in The United States Naval Flight Surgeon Handbook ${ }^{7}$ will be utilized and were based on recommendations from Brooke Army Medical Center. The Handbook recommends 2-4 $\mathrm{mL} /(\mathrm{kg} \% \mathrm{TBSA})$ of Lactated Ringer's (LR) in the first $24 \mathrm{hrs}$, with half of that amount given in the first $8 \mathrm{hrs}$. Recommendations for the second 24 hours are $0.5 \mathrm{~mL} /(\mathrm{kg} \% \mathrm{TBSA}$ ) of $5 \%$ albumin in Lactated Ringer's (200 cc $25 \%$ albumin in $800 \mathrm{cc}$ of LR) and D5W at $2-4 \mathrm{~mL} /(\mathrm{kg} \% \mathrm{TBSA})$, which is the same fluid hourly infusion rate as the first 24 hours. Albumin is not recommended, however, for inclusion in Exploration missions due to uncertain efficacy, storage life concerns, and radiation concerns.

A $100 \mathrm{~kg}$ male with a $40 \%$ burn surface area would require $16 \mathrm{~L}$ of LR in the first 24 hours according to the Parkland and Naval formula (8-16 L Naval), with $8 \mathrm{~L}$ given in the first 8 hours. The second 24 hours would require 8-16 L of D5W and $2 \mathrm{~L}$ of $5 \%$ albumin according to Naval guidelines. As mentioned above, NASA will not plan to include the albumin for exploration class missions. The D5W rate is adjusted by monitoring urine output, but these tests may not be available on exploration missions. Fluid treatment beyond 48 hours would only be required if the patient is physically unable to eat and drink. The maximum total fluid requirements would be $16 \mathrm{~L}$ of $\mathrm{LR}$ and $16 \mathrm{~L}$ of D5W, for a total of $32 \mathrm{~L}$.

\section{B. Acute Anemia}

Acute anemia due to blood loss requires fluid treatment to maintain the intravascular volume. The blood loss can occur from a major laceration, puncture wound, or other causes. Crystalloids are the appropriate treatment for moderate volume loss, but blood transfusions should normally be considered after $2 \mathrm{~L}$ of crystalloids. The general terrestrial rule of thumb is 1 unit of blood for every 3 units of crystalloid. We made the assumption for this study, 
however, that blood would not be carried on board. Hemoglobin-based oxygen carriers (HBOCs) are a potential alternative for whole blood in cases of severe blood loss, assuming a sufficient supply while the body regenerates the red blood cells. Blood loss of $40 \%$ or greater (Class IV shock) requires prompt resuscitative measures to avoid patient demise.

Acute anemia generally utilizes only $2 \mathrm{~L}$ of crystalloids before considering blood or HBOC transfusion, although for the $100 \mathrm{~kg}$ male $3 \mathrm{~L}$ of crystalloids would provide the same dilution. Normal Saline is the most commonly used solution in emergency rooms. If the hemoglobin level is allowed to decrease from $15 \mathrm{~g} / \mathrm{dL}$ to $7 \mathrm{~g} / \mathrm{dL}$ without oxygen-carrier transfusion, 53\% of the blood volume could be replaced with fluid. A $100 \mathrm{~kg}$ male has $7.1 \mathrm{~L}$ of blood, compared to the typical $70 \mathrm{~kg}$ male with $5 \mathrm{~L}$ of blood. These volumes do not account for any possible changes due to chronic hypogravity or hypoxic cabin environments.

A $100 \mathrm{~kg}$ male could receive $4 \mathrm{~L}$ of fluid while maintaining a hemoglobin concentration above $7 \mathrm{~g} / \mathrm{dL}$, and $5 \mathrm{~L}$ of fluid and maintain a hemoglobin concentration of $5 \mathrm{~g} / \mathrm{dL}$. Because crystalloids tend to leave the vascular system and diffuse to the interstitial volume, additional fluid is required to maintain proper intravascular volume while the patient recovers. Assuming a 30\% intravascular volume loss is acceptable, a maximum $66 \%$ blood loss to maintain sufficient hemoglobin, and a $20 \%$ intravascular crystalloid retention, a maximum $12 \mathrm{~L}$ of Normal Saline would be required for the worst case. A patient would be physically unable to survive without an oxygen-carrier transfusion if the blood loss was more severe. Only 3-5 L would be delivered immediately, with the remaining amount delivery as the crystalloid leaves the intravascular volume and blood pressure drops. Infusing $12 \mathrm{~L}$ of crystalloid could introduce other serious problems, and should be considered an absolute worst case, to be used only if blood or HBOCs are not available.

\section{Drug Delivery}

Certain medications specify delivery by IV fluid. This restriction is often due to the need for a prolonged delivery timeline, and may be avoided in some emergencies by multiple delayed injections. The ability to provide drugs by IV does have procedural advantages in requiring less human involvement, eliminates multiple injection sites, and provides versatility in varying the drug introduction rate. Currently, 4 drugs that are on the ISS require some volume of IV fluid for delivery, and 4 more are under consideration. Longer duration missions with no chance of timely transport will presumably carry more such drugs. There are many conditions in the PCDB that may require IV drug delivery, from severe conditions such as cardiac arrest to less life-threatening conditions such as various forms of infections. To provide a quick method for administering medicines if needed, starting an IV line upon admission is standard procedure in most terrestrial emergency rooms. Normal Saline is often preferred as it avoids any potential problems with excess glucose. Lactated Ringer's cannot be injected at the same site with blood because of interactions with stabilizing chemicals. ${ }^{8,9}$ Many of the drugs requiring IV delivery would be administered in one dose, or given over a relatively short duration. They would require only 1-2 L of fluid for injection. Conditions requiring long-term IV drug delivery typically require 1-2 L per day, with Normal Saline as the generally preferred diluent.

\section{Bone Fracture}

Fractures of major bones of the body such as the femur, radius, or hip could require fluid treatment. Major blood vessels could be severed, resulting in blood loss and acute anemia. The blood loss is generally internal to the body. Treating severe fractures requires open reduction and realignment; these procedures are simple enough for consideration on exploration missions but this minor surgery entails additional blood loss. A fracture of the femur is more severe since major arteries are subject to severing. A femur fracture can cause internal blood loss can be as high as 2-3 L, with compartment syndrome a major concern..

Fractures of the long bones in the arms and lower legs can cause internal blood loss and sequestration, but generally do not require fluid treatment. A worst-case scenario for these fractures also includes open reduction and requires up to $2 \mathrm{~L}$ of NS. Fractures of the femur can be far more severe. If a fasciotomy is not attempted to reduce intracompartmental pressure and avoid tissue necrosis, the treatment fluid volume required is bounded by the need to prevent excessive hemodilution while preserving adequate blood pressure. This internal blood loss limit is lower than that of the external blood loss case discussed in regards to acute anemia. An estimate of the maximum amount of fluid required to treat a femur fracture without a fasciotomy is $8 \mathrm{~L}$ of NS (again, assuming blood is not available on board).

\section{E. Fluid Maintenance}

Humans require water to replace that lost during the day to the environment. Water is released through bodily waste, through the skin as a heat regulation mechanism, and through the lungs due to evaporative losses during 
breathing. Normally water replacement is $2 / 3$ from drink and $1 / 3$ from food. A patient physically unable to eat or drink must have water, electrolytes, and caloric requirements replaced intravenously. The most common method to calculate requirements is the Holliday-Segar Method. ${ }^{10}$ This method is widely accepted, but was developed from pediatric studies in patients up to $70 \mathrm{~kg}$ in weight, and has not been verified for low-pressure environments. Hypogravity is known to at least temporally affect body fluid levels, and a low-pressure cabin might affect the fluid loss through changes in the respiration and perspiration rates. For humans $>20 \mathrm{~kg}$, the daily requirements are ${ }^{10}$

- $1500 \mathrm{kcal}+20 \mathrm{kcal} / \mathrm{kg}$ over $20 \mathrm{~kg}$,

- $1 \mathrm{cc}$ water/kcal,

- $3 \mathrm{mEq} \mathrm{Na} / 100 \mathrm{cc}$ water,

- $2 \mathrm{mEq} \mathrm{K} / 100 \mathrm{cc}$ water, and

- $2 \mathrm{mEq} \mathrm{Cl} / 100 \mathrm{cc}$ water.

A $100 \mathrm{~kg}$ male would require $3.1 \mathrm{~L}$ of fluid per day according to the Holliday-Segar formula. The solution would typically be D5 $1 / 2 \mathrm{NS}+20 \mathrm{mEq} \mathrm{KCl} / \mathrm{L}$. This should continue for not longer than 10 days before alternative treatments are implemented due to the lack of calories and other trace chemicals. Assuming the patient would be treated for no longer than 14 days worst case, $44 \mathrm{~L}$ of fluid would be required.

\section{Exploration Mission Fluid Requirements}

NASA is currently considering and planning a wide variety of missions that vary in duration from several days to many months in the case of a Martian voyage. The missions also differ from one another by the ease with which a patient can be returned to earth. These two factors, duration and ease of return, dictate different fluid generation and mixing requirements for each mission, even for the same set of patient conditions. There will also be considerable differences in the mass allotted for medical supplies to treat patient conditions. In this section, we outline treatment timelines and fluid needs for four different missions, one to ISS, a lunar visit, a lunar habitat, and a trip to Mars.

\section{A. Fluid Requirements for ISS}

The long duration nature of the mission allows for some flexibility in the treatment timeline. The time, space, and potentially the supplies required are available to treat the patient in-situ. Patients could be allowed to stabilize after major injury prior to transport to earth. The transport time would be a matter of hours, but loading time may be extended due to issues of moving the patient. For a worst case condition, the patient could be stabilized for up to two weeks prior to transport.

The critical fluid patient conditions for an ISS mission are severe burns, acute anemia, major fractures, and IV maintenance. It is expected that most medical events would involve only one patient, but a major fire could encompass multiple crewmembers. The potentially long stabilization time makes maintenance the largest potential fluid requirements event. Based on more detailed analysis ${ }^{5}$, Table 1 illustrates the ISS fluid requirements.

\begin{tabular}{|c|c|c|c|c|}
\hline Burn (2 patients) & $\begin{array}{l}\text { Major Long } \\
\text { Bone Fracture }\end{array}$ & $\begin{array}{l}\text { Trauma with } \\
\text { Acute Anemia }\end{array}$ & $\begin{array}{c}\text { Illness with Drug } \\
\text { Delivery }\end{array}$ & $\begin{array}{l}\text { Trauma or } \\
\text { Illness with } \\
\text { Maintenance }\end{array}$ \\
\hline $\begin{array}{l}24 \text { L LR } \\
77 \text { L D5KS }\end{array}$ & 8 L NS & $\begin{array}{l}12 \text { L NS } \\
9 \text { L D5KS }\end{array}$ & 16 L NS & $\begin{array}{l}4 \text { L NS } \\
9 \text { L D5KS }\end{array}$ \\
\hline
\end{tabular}

Table 1: Fluid requirements to treat two crewmembers with major injuries/illnesses on the ISS.

\section{B. Lunar Sortie}

The short duration of the mission limits the potential time for patient stabilization prior to Earth return. It also lessens the chance of multiple events during the mission. A maximum of 7 days can be spent on the surface, and transport back to Earth can occur from any site at any time in 5 days or less. Medical events that happen during the initial transit to the moon can utilize the free-return abort mode as in Apollo 13, limiting the maximum total treatment time to 6 days for an event in the early stages of the mission when a direct-return is not possible. The limited supplies in these missions will restrict the time allowed for stabilization prior to starting return. Requirements in this document assume that transport will begin 24 hours after any major incident. 
The critical fluid patient conditions are burns, acute anemia, major fracture, and maintenance. The maintenance fluid requirements are lower than for the ISS mission due to the fewer days of treatment (6 versus 14). Severe illness or infections that would require long-term drug delivery are not considered likely on these short duration missions if astronauts are effectively pre-screened for health conditions.

The detailed analysis given in reference [5] yielded the following estimate of Lunar Sortie requirements.

\begin{tabular}{|l|c|c|c|}
\hline \multicolumn{1}{|c}{ Burn (1 patient) } & \multicolumn{1}{c}{$\begin{array}{c}\text { Major Long Bone } \\
\text { Fracture }\end{array}$} & \multicolumn{1}{c|}{$\begin{array}{c}\text { Trauma with Acute } \\
\text { Anemia }\end{array}$} & \multicolumn{1}{c|}{$\begin{array}{c}\text { Trauma or Illness } \\
\text { with Maintenance }\end{array}$} \\
\hline 16 L LR & $8 \mathrm{~L} \mathrm{NS}$ & $12 \mathrm{~L} \mathrm{NS}$ & $2 \mathrm{~L} \mathrm{NS}$ \\
28 L D5KS & & $9 \mathrm{~L} \mathrm{D5KS}$ & 6 L D5KS \\
\hline
\end{tabular}

Table 2: Fluid requirements to treat two crewmembers with major injuries/illnesses on the Lunar Sortie.

\section{Lunar Outpost}

The lunar habitat missions currently envisioned will require a crew of 4 occupying an outpost for up to 6 months. A continuous human presence on the moon will be accomplished by crew rotation. The supplies available for medical treatment may well be increased over the short duration missions, but exact parameters have not been established. The vehicles developed for the lunar sortie will be used for crew rotation. This implies a maximum 5 days from return decision to touchdown. One of the purposes of this class of missions is validating technologies required for Martian exploration, including medical capabilities. These missions are the best opportunities for evaluating medical technologies and procedures for Mars missions when no return will be possible.

The treatment timeline is similar to that outlined for the ISS. The facilities available will allow time for patient stabilization prior to transport if that is the best course of action. Due to the relatively long transportation time with limited facilities, in-situ treatment could produce better outcomes than evacuation. Requirements in this document envision that a patient could stabilize for up to 14 days before a 5-day evacuation. Not considered are potential mission scenarios with an extended duration rover away from the habitat for several days. Table 3 gives the requirements. $^{5}$

\begin{tabular}{|c|c|c|c|c|}
\hline Burn (2 patients) & $\begin{array}{l}\text { Major Long } \\
\text { Bone Fracture }\end{array}$ & $\begin{array}{l}\text { Trauma with } \\
\text { Acute Anemia }\end{array}$ & $\begin{array}{c}\text { Illness with Drug } \\
\text { Delivery }\end{array}$ & $\begin{array}{l}\text { Trauma or } \\
\text { Illness with } \\
\text { Maintenance }\end{array}$ \\
\hline $\begin{array}{l}24 \text { L LR } \\
92 \text { L D5KS }\end{array}$ & $8 \mathrm{~L} \mathrm{NS}$ & $\begin{array}{l}12 \text { L NS } \\
9 \text { L D5KS }\end{array}$ & 16 L NS & $\begin{array}{l}4 \text { L NS } \\
9 \text { L D5KS }\end{array}$ \\
\hline
\end{tabular}

Table 3: Fluid requirements to treat two crewmembers with major injuries/illnesses during a Lunar Habitat mission.

\section{Mars Exploration}

Mars exploration is planned as a conjunction-class mission, with a 6 month transit to and from Mars, and an 18 month stay. A crew of 6 will be included on this 2.5 year mission. No early return is possible in the case of an emergency. All medical conditions must be treated on-site with available resources. This mission will include extended time in both microgravity and $0.38 \mathrm{~g}$. A pre-deployed surface habitat, and a pre-deployed Mars Lander will precede crew launch. Separate medical equipment could be provided for in both the transfer vehicle and the habitat.

The inability to transport injured crew to Earth facilities requires that all medical conditions, except those at the very beginning or end, must be treated to recovery, supply exhaustion, or death of the patient. The total mission length is similar to the combination of 2 continuous ISS expeditions in microgravity and 3 continuous lunar habitat expeditions in partial gravity. The medical conditions that may be encountered on the Martian surface are similar to those for the lunar habitat. The microgravity transit will presumably not include any construction activities like on ISS, but could include repair EVAs. Mars Exploration Requirements are shown in Table 4. 


\begin{tabular}{|c|c|c|c|c|}
\hline Burn (2 patients) & $\begin{array}{l}\text { Major Long } \\
\text { Bone Fracture }\end{array}$ & $\begin{array}{l}\text { Trauma with } \\
\text { Acute Anemia }\end{array}$ & $\begin{array}{c}\text { Illness with Drug } \\
\text { Delivery }\end{array}$ & $\begin{array}{l}\text { Trauma or } \\
\text { Illness with } \\
\text { Maintenance }\end{array}$ \\
\hline $\begin{array}{l}24 \text { L LR } \\
148 \text { L D5KS }\end{array}$ & $8 \mathrm{~L} \mathrm{NS}$ & $\begin{array}{l}12 \text { L NS } \\
16 \text { L D5KS }\end{array}$ & $22 \mathrm{~L} \mathrm{NS}$ & $\begin{array}{l}4 \text { L NS } \\
16 \text { L D5KS }\end{array}$ \\
\hline
\end{tabular}

Table 4: Fluid requirements to treat two crewmembers with major injuries/illnesses during a Mars mission.

\section{E. Summary of Fluid Requirements}

Within each of the missions, several scenarios were evaluated for the overall medical fluid requirements. These scenarios included a single event, a single major event with one minor event, a single major event with a burn event, and other combinations described in reference [5]. Total mission fluid requirements were then developed based on treating various combinations of medical events. During this development, it was recommended that Lactated Ringer's and Normal Saline be considered nearly interchangeable electrolytes to reduce the overall volume requirements.

Table 5 gives the final recommended volumes for the various missions. The longer duration missions include fluid to treat multiple medical events. Mass constraints may limit the fluid provided on missions, so a minimum fluid recommendation is also included. Normal Saline, whether premixed or mixed on-board during an emergency, is the only electrolyte included in the minimum recommendations. The ISS minimum recommendation would be sufficient to treat any one medical event excluding maintenance fluids (dextrose is carried to meet the 48 hour fluid requirement for burns). The lunar sortie minimum recommendation would cover any one event except a burn event, and excluding maintenance fluids. It would provide the minimum volume recommendations for a $100 \mathrm{~kg}$ patient with $30 \%$ burns, although not the caloric intake provided by D5KS and not any fluids beyond the first 48 hours. The lunar habitat minimum recommendation would treat any one event, excluding maintenance requirements. The minimum recommended for a Mars mission is more generous. It would cover the initial fluid requirements of the burn event with two patients, and the initial requirements of any other one event. Maintenance fluids for a total of 15 days are also included to treat the 3 potential patients.

\begin{tabular}{|c|c|c|c|}
\hline Mission & $\begin{array}{c}\text { Recommended Event } \\
\text { Coverage }\end{array}$ & $\begin{array}{c}\text { Fluid Volume } \\
\text { Recommendation }\end{array}$ & $\begin{array}{l}\text { Minimum Fluid } \\
\text { Recommendation }\end{array}$ \\
\hline ISS & $\begin{array}{c}\text { Any one minor event } \\
\text { and any one major } \\
\text { event }\end{array}$ & $\begin{array}{l}20 \text { L LR } \\
20 \text { L NS } \\
86 \text { L D5KS } \\
126 \text { L total }\end{array}$ & $\begin{array}{l}24 \text { L NS } \\
24 \text { L D5KS } \\
48 \text { L total }\end{array}$ \\
\hline Lunar Sortie & Any one event & $\begin{array}{l}8 \text { L LR } \\
8 \text { L NS } \\
28 \text { L D5KS } \\
44 \text { L total }\end{array}$ & $\begin{array}{l}12 \mathrm{~L} \mathrm{NS} \\
12 \mathrm{~L} \text { total }\end{array}$ \\
\hline Lunar Habitat & $\begin{array}{c}\text { Any one minor event } \\
\text { and any one major } \\
\text { event }\end{array}$ & $\begin{array}{l}20 \text { L LR } \\
20 \text { L NS } \\
101 \text { L D5KS } \\
141 \text { L total }\end{array}$ & $\begin{array}{l}24 \text { L NS } \\
24 \text { L D5KS } \\
48 \text { L total }\end{array}$ \\
\hline Mars Exploration & $\begin{array}{l}\text { Any two minor events } \\
\text { and one burn event }\end{array}$ & $\begin{array}{l}34 \text { L LR } \\
34 \text { L NS } \\
180 \text { L D5KS } \\
248 \text { L total }\end{array}$ & $\begin{array}{l}36 \mathrm{~L} \mathrm{NS} \\
69 \mathrm{~L} \mathrm{D} 5 \mathrm{KS} \\
105 \mathrm{~L} \text { total }\end{array}$ \\
\hline
\end{tabular}

Table 5: Final fluid volume recommendations for exploration missions. 


\section{Considerations for Creating Water for Injection}

When developing a Water For Injection (WFI) production system for NASA's exploration missions, the unique operational environment raises additional challenges not encountered when developing a ground-based system and requires special considerations. In addition, the initial water source supplied to the system may have important differences from the water that ground-based systems typically employ. The gravity level, radiation level, and sealed environment all raise concerns about microbial contamination and how to maintain sterility of the system in conditions not previously encountered by WFI systems. These concerns are in addition to the normal NASA concerns on minimizing weight, volume, and power, while maximizing reliability.

\section{A. Water Quality Requirements}

The requirements for WFI and sterile WFI are set out in the United States Pharmacopeia (USP). ${ }^{11}$ That document contains specific requirements that must be met, as well as general requirements that can be difficult to quantify. The general, unquantified requirements could be problematic with a unique system specific to NASA's needs. NASA's needs may well be better met by a new type of system, but defining equivalent performance of existing systems is a challenge. As an example, the USP standard requires that source water meet Environmental Protection Agency (EPA) potable water standards. The EPA does not have standards on all possible contaminates, such as iodine and silver because these biocides are not normally used in public water systems. Biocides are not allowed in water for injection and must be removed. Reference [5] discusses in detail the various agencies and regulations governing water quality and allowed contaminant levels in water to be used for different purposes.

\section{B. Water Sources}

While using potable water as the source to generate WFI is obvious, other potential sources exist. Short duration missions could use fuel cells, such as in the Shuttle, to generate high purity water. Oxygen generation via electrolysis for moderate duration missions uses potable water with an additional deionizing bed to remove the iodine biocide. This product water could also be used to generate WFI. A generic emergency water source to be used for oxygen generation, medical emergencies, or replenishing potable water stores may be a viable option for moderate to long duration missions. Water obtained from in-situ resource utilization would presumably go through processing to bring quality up to potable water standards.

Potable water on the ISS is used for drinking and hygiene. NASA potable water must meet requirements as set out in NASA SSP $41000^{12}$, which is different than EPA standards. There is some overlap in the two standards, but NASA's standards cover contaminants specific to spacecraft water, and do not have requirements to eliminate contaminants commonly found in public water systems. Overlapping contaminant standards are generally stricter in NASA's requirements, but this is not true for all substances.

Oxygen production requires higher purity water than NASA potable water. The Oxygen Generation System (OGS) flight hardware generates oxygen via electrolysis and was flown to ISS on STS-121 this year. This system is designed to utilize NASA potable water provided by the Water Recovery System. An internal deionizing bed removes the iodine biocide, as well as other ions ${ }^{13}$. This treated water remains internal to the OGS, and is not normally available for other uses.

\section{Production Timeline}

The choice of a system to produce WFI is critically tied with the timeline over which water would be available. Systems that produce water more slowly must have some sort of stored capacity to meet potential requirements for an initial bolus in the case of an emergency. Such a contingency is at odds with the general NASA philosophy to eliminate the mass of stored water. Production timelines for various systems are described below.

An on-demand system would require a high production rate in order meet the initial needs, on the order on 4 $\mathrm{L} / \mathrm{hr}$. This high production rate may preclude certain technologies from consideration. Stowing limited supplies on the order of 2-10 L to handle the initial needs, and then producing fluids at a moderate rate to keep the supplies replenished is an alternative to a large capacity on demand system. Typical IV fluid maintenance rates are 4 L/day, although certain conditions could require more fluids in the short term. An online system available for production at any time, or a limited use system that produces a fixed quantity of fluid before requiring consumable replacements is another option. Cartridge-type systems use consumables to remove and store the contaminants. Cartridge systems typically treat limited quantities of fluid, on the order of $10 \mathrm{~L}$. Such systems could be developed for one time use, where a cartridge is rated to purify a prescribed volume of fluid and is also rated for a limited duration of dry, sterile storage. 


\section{Solution Production}

The final product for ultimate use is a medical solution. This requires adding and mixing the constituents, such as sodium chloride, glucose, or other pharmaceuticals. The physical state of the constituents directly affects the mixing method and indirectly affects the water production method. The mixing time also influences the delivery timeline. Time to treatment can be critical in an emergency. To fit within a therapeutic window, longer mixing times reduce the time available for WFI production. A long mixing time may require a large capacity production system to decrease the WFI production time. Mixing time is less critical for a system with emergency stores. The method appropriate for mixing the solution to final form is the subject of an ongoing project at GRC. ${ }^{14}$

\section{E. Hypogravity Production Challenges}

Microgravity poses operational challenges for any fluid system. Potential problems in an IV system arise in all phases of operation, from production to storage to handling. There are also potentially unique sterility issues arising from microgravity operation. Addressing challenges induced by hypogravity issues should be tackled early in the design phase, rather than attempting to add ad hoc solutions later in the development process. Design challenges due to altered gravity are frequently of such magnitude that they can only be effectively addressed in the design phase. In general, partial gravity systems are somewhat easier to design and test, but still require careful analysis. A more detailed discussion of the difficulties hypogravity imposes is given in reference [5], while a summary is provided below.

Many of the microgravity fluids issues arise when a liquid-vapor interface is present. The interface may be present by design, or as an off-nominal condition. All production methods are potentially affected by the presence of bubbles in the system. The location of bubbles in microgravity is much more difficult to predict because, unlike normal gravity, the system has no top. Thus, mitigating bubble problems is harder in microgravity. Bubbles can cause pump problems such as loss of prime, which could be mitigated by less susceptible positive displacement pumps. Adsorbent media such as charcoal filters or ion-exchange resins are only effective when water is able to pass through them. Such media are rendered ineffective when the gas bubbles effectively channel the liquid flow around a dry volume, or could result in a stagnant flow, which can then become a bacterial breeding ground. Filters and membranes can be rendered ineffective for similar reasons.

Many ground-based systems, and some proposed microgravity systems have a storage vessel for limited WFI storage. Storage may not be required for an on-demand system, but a system designed for gradual replacement may perform better by storing small volumes of WFI prior to filling IV bags. Filling, venting, and removal from containers in microgravity is complicated by ensuring the proper location of the liquid and vapor present. Capillary devices are often used for liquid management.

Using devices at various places in the system to trap and remove the bubbles could alleviate Microgravity handling challenges. Bubble traps could remove inlet bubbles from source water prior to entering the WFI production system, prior to any storage container, the mixing device, and/or prior to actual use. These traps could be used constantly, such as the inlet trap, be required only during a priming operation, or require monitoring and action if the closed system is breached and a bubble enters the system. Some production methods, such as distillation, may require more rigorous bubble control methods. There may also be microgravity-handling issues with particulates in the system. The filter-based technologies may have particulates released from the media that may be more readily transported in microgravity, depending on filter orientation. ${ }^{15}$

Maintaining sterility of a medical water generation system is critical to its ultimate performance. This task is challenging under normal gravity, and presents some unknown issues in microgravity. The environmental effects of microgravity and increased radiation may cause differences in microbial growth, as well as potentially increase mutation. Cell culture experiments on Shuttle and ISS have shown measurable differences in microgravity, but operational experience on Mir and ISS has not shown noticeable microbial differences with gravity level. It is not expected that microgravity operation will present any additional sterility challenges.

\section{Potential Production Technologies}

Table 6 gives a summary of the technologies that could be used to generate WFI during an emergency and for subsequent maintenance needs. ${ }^{5}$ (Note that the SBIR level technologies are not included in the table and the reader is referred to reference [5] for those). Only two technologies are currently approved for WFI, distillation and reverse osmosis. Unfortunately, both suffer from disadvantages that make them difficult to adapt to spacecraft use. Distillation requires a large amount of energy, a cooling surface, and gravity or other means of separating the gas from the liquid. RO, meanwhile needs a relatively high-pressure water source, and faces sterilization issues for repeated use. 
Currently the technology next closest to meeting USP standards is a combination of filtration (to remove larger contaminants) and adsorption to remove specific molecular and living species (i.e., viruses). While not yet approved for parenteral use, vendors are making improvements that may allow this use in the future. Forward osmosis (FO) could likely be approved for parenteral use, given that RO is approved, but is limited to producing concentrated solutions and not nearly as flexible as technologies that produce pure water from which the desired solution can be made. FO may find a niche application in WFI. The remaining three technologies, membrane distillation, osmotic distillation (which, like FO, can only produce concentrated solutions), and nano-filtration offer some potential advantages of weight and power, but are still in the development stage and would require more extensive work to produce WFI in space.

A future trade study is planned to identify, evaluate in more detail, and draw conclusions about these potential WFI production methods. The trade study will select the method most appropriate for the various DRMs, and provide estimates of expected performance. Other technologies may be identified during the trade study and included as well. The potential technologies will be quantitatively evaluated to present a non-biased ranking. The selection criteria will include parameters such as production rate, sterility, mass, consumables, hypogravity confidence, operations, and development ease.

\begin{tabular}{|c|c|c|c|c|c|c|}
\hline $\begin{array}{c}\text { Water } \\
\text { Generation } \\
\text { Method }\end{array}$ & $\begin{array}{l}\text { Contaminants } \\
\text { removed }\end{array}$ & $\begin{array}{l}\text { In use now } \\
\text { for WFI }\end{array}$ & $\begin{array}{l}\text { Rate of } \\
\text { generation }\end{array}$ & $\begin{array}{c}\text { Energy } \\
\text { needed for } \\
\text { generation }\end{array}$ & Sterilization & $\begin{array}{l}\text { Other needs or } \\
\text { limitations }\end{array}$ \\
\hline Distillation & $\begin{array}{l}\text { Essentially } \\
\text { everything }\end{array}$ & Yes & $\begin{array}{lr}\text { High; } & \text { many } \\
\text { gallons } & \text { per } \\
\text { hr. } & \end{array}$ & $13 \mathrm{Wh} /$ liter & $\begin{array}{l}\text { May need to } \\
\text { sterilize cold } \\
\text { lines. }\end{array}$ & $\begin{array}{l}\text { Need a cool } \\
\text { surface for } \\
\text { condensation. } \\
\text { Conventional } \\
\text { separation } \\
\text { requires gravity } \\
\text { to work }\end{array}$ \\
\hline $\begin{array}{l}\text { Reverse } \\
\text { Osmosis }\end{array}$ & $\begin{array}{l}\text { Bacteria, } \\
\text { endotoxins } \\
\text { Viruses } \\
\text { Large molecules } \\
\text { solids } \\
\text { Salts to some } \\
\text { extent }\end{array}$ & $\begin{array}{l}\text { Yes. Also } \\
\text { was tested } \\
\text { by KSC for } \\
\text { space use } \\
\text { and met } \\
\text { most USP } \\
\text { standards } \\
\end{array}$ & $\begin{array}{l}\text { several } \\
\text { gallons/day }\end{array}$ & $\begin{array}{l}\text { Need } \\
\text { pressurized } \\
\text { water (120 psi } \\
\text { or more) }\end{array}$ & $\begin{array}{l}\text { need to } \\
\text { sterilize } \\
\text { membrane and } \\
\text { whole system } \\
\text { periodically }\end{array}$ & \\
\hline Adsorption & $\begin{array}{l}\text { Most } \\
\text { contaminants can } \\
\text { be removed, but } \\
\text { adsorber(s) must } \\
\text { be chosen for } \\
\text { specific } \\
\text { contaminants }\end{array}$ & No & $\begin{array}{lr}\text { Depends } & \text { on } \\
\text { size } & \text { of } \\
\text { cartridge. } & 4.5 \\
\text { l/hour } & \text { is } \\
\text { available } & \end{array}$ & $\begin{array}{l}\text { Need low } \\
\text { pressure } \\
\text { water of a } \\
\text { couple psi }\end{array}$ & $\begin{array}{l}\text { cartridge can } \\
\text { be stored } \\
\text { sterile, but only } \\
\text { used once }\end{array}$ & $\begin{array}{l}\text { Current cartridge } \\
\text { can treat } 3 \text { liters, } \\
\text { then must be } \\
\text { disposed }\end{array}$ \\
\hline Filtration & $\begin{array}{l}\text { Bacteria } \\
\text { Endotoxins } \\
\text { Solids }\end{array}$ & No & $\begin{array}{l}\text { Varies with } \\
\text { filter. Ex } 0.7 \\
1 / \mathrm{m} \text { for } 5 \mathrm{psi}\end{array}$ & $\begin{array}{l}\text { Need } \\
\text { pressurized } \\
\text { water source }\end{array}$ & $\begin{array}{l}\text { Chemical } \\
\text { treatment or } \\
\text { Disposal }\end{array}$ & \\
\hline $\begin{array}{l}\text { Forward } \\
\text { Osmosis }\end{array}$ & $\begin{array}{l}\text { Same as reverse } \\
\text { osmosis }\end{array}$ & No & $0.8 \mathrm{l} / \mathrm{hr}$ & none & $\begin{array}{l}\text { Use once, then } \\
\text { dispose. }\end{array}$ & $\begin{array}{l}\text { Cannot produce } \\
\text { pure water, only } \\
\text { concentrated } \\
\text { solutions. }\end{array}$ \\
\hline $\begin{array}{l}\text { Membrane } \\
\text { Distillation }\end{array}$ & $\begin{array}{l}\text { Essentially } \\
\text { everything, but } \\
\text { still under } \\
\text { development }\end{array}$ & No & Not yet tested & $\begin{array}{l}\text { Lower than } \\
\text { traditional } \\
\text { distillation }\end{array}$ & Not yet tested & $\begin{array}{lr}\text { Need a cool } \\
\text { surface } \\
\text { condensation }\end{array}$ \\
\hline $\begin{array}{c}\text { Osmotic } \\
\text { Distillation }\end{array}$ & $\begin{array}{l}\text { Essentially } \\
\text { everything }\end{array}$ & No & $\begin{array}{l}\text { N/A, but } \\
\text { likely slow }\end{array}$ & Low & Not yet tested & $\begin{array}{l}\text { No high pressure } \\
\text { as in RO } \\
\text { Cannot produce } \\
\text { pure water, only } \\
\text { solutions }\end{array}$ \\
\hline $\begin{array}{c}\text { Nano } \\
\text { Filtration }\end{array}$ & $\begin{array}{l}\text { Still in the } \\
\text { experimental } \\
\text { phase - actually } \\
\text { being developed } \\
\text { to cleanse blood }\end{array}$ & No & $\begin{array}{lr}\text { N/A, } & \text { but } \\
\text { similar } & \text { to } \\
\text { kidney } & \\
\text { function } & \end{array}$ & $\begin{array}{l}\text { low pressure } \\
\text { fluid needed }\end{array}$ & $\begin{array}{l}\text { N/A } \\
\text { probably need } \\
\text { to dispose }\end{array}$ & $\begin{array}{l}\text { No large-scale } \\
\text { device ever made }\end{array}$ \\
\hline
\end{tabular}

Table 6: Efficacy of various methods of water purification. 


\section{Recommendations}

NASA's Vision for Space Exploration has initiated new efforts to determine what technologies will be required for exploration of the Moon and Mars, and to define how these technologies will be developed and validated. Medical requirements and capabilities are being developed as part of this process. In particular, the necessity and required volumes for medical intravenous fluids are presented in this paper.

Terrestrial hospitals have a wide variety of fluids for medical use, but the mass and storage requirements limit what NASA may carry. In particular, human blood or blood products cannot be provided on exploration missions because of limited storage life and refrigeration capabilities. HBOCs are under development as a substitute, but have not reached sufficient maturity to be included in NASA's planning at this time. Colloids are also commonly used for terrestrial medical treatment, but recent research questions the efficacy of colloids over crystalloids. It is recommended that 3 types of fluids be available for use in NASA's exploration missions: Lactated Ringer's (LR), Normal Saline (0.9\%) (NS), and 5\% Dextrose with 1/4 NS and $20 \mathrm{mEq} \mathrm{KCl} \mathrm{(D5KS).} \mathrm{These} \mathrm{are} \mathrm{the} \mathrm{most} \mathrm{common}$ fluids used for burns, trauma and medication, and maintenance requirements respectively. Lactated Ringer's and Normal Saline are often considered nearly interchangeable during treatment, and it is recommended that they be considered fully interchangeable for high-volume medical fluid treatments during exploration missions to reduce the overall volume requirements. It is also recommended that the medical community evaluate whether the LR and NS requirements can be met by one electrolyte to further reduce the logistics requirements.

The requirements for medical fluids were developed by evaluating the patient conditions in the PCDB. Five generic situations were identified to quantify fluid requirements, rather than develop fluid requirements for each specific condition. These five conditions were 2 nd and 3rd degree skin burns, acute anemia, drug delivery, major bone fracture, and fluid maintenance. Actual medical events can require fluid treatment for several of these generic conditions. Typical medical events were postulated and analyzed to determine fluid requirements for the various exploration missions. The maximum fluid requirement scenario for each mission was always a major fire, possibly injuring 2 crew members, requiring fluid treatment followed by maintenance fluids as the patient(s) recover(s). This scenario is often considered as either the driver for fluid volume requirements, or so severe as to preclude any treatment beyond the most basic. Because space exploration has already had several fire or explosion events (Apollo 1, Apollo 13, and Mir NASA-3), prudence dictates planning for the possibility. Additionally, the planned low-pressure, oxygen-rich environment in the new spacecraft increases the fire hazard over ISS, and surface exploration is EVA intensive in a pure-oxygen spacesuit environment.

The recommended fluid volumes are detailed in Table 5. These recommendations should be considered as an upper bound of what would be required. Mission constraints may limit the supplies provided onboard, while accepting the subsequent increase in risk. The requirements are similar for the ISS and lunar habitat missions, with somewhat increased requirements for a Mars Mission. The lunar sortie requirements are substantially less and may require a different type of fluid production system if fluids are provided.

It is recommended that a system capable of generating $130 \mathrm{~L}$ of fluid for two time-separated events should be developed for ISS and lunar habitat missions. The water generation system should have the capability of generating $100 \mathrm{~L}$ of medical water at any time after one minor event, or have the capability to produce and store sufficient solutions immediately after the first event. Concentrate or powder and associated supplies should be available to produce $15 \mathrm{~L} \mathrm{LR}, 15 \mathrm{~L} \mathrm{NS}$, and 100 D5KS. An 8-hour contingency supply of $6 \mathrm{~L} \mathrm{LR}, 6 \mathrm{~L} \mathrm{NS}$, and $2 \mathrm{~L}$ D5KS should be carried as stores. Note that when LR and NS are considered nearly interchangeable as recommended, the 8-hour contingency supply is the same as a 2-hour contingency supply for all of the DRMs. The system would preferably have the ability to produce new contingency stores with a shelf life of 6 months after a minor medical event occurs, otherwise new stores will have to be shipped to ensure a sufficient supply. A Mars fluid system would have the additional requirement of being capable of generating replacement contingency stores with at least a 6month shelf life

The lunar sortie has a much reduced volume requirement, and less concern with long-term sterility. It is probably not realistic to carry an 8-hour contingency supply, so a 1-hour supply of 4 L NS is recommended. The ability to produce $40 \mathrm{~L}$ of solution as $8 \mathrm{~L} \mathrm{LR}, 4 \mathrm{~L} \mathrm{NS}$, and $28 \mathrm{~L} \mathrm{D5KS}$ to handle any one event is recommended.

The solutions produced should meet USP standards to ensure the best possible medical care is being provided. There is some concern because the USP standards are defined mainly from the process used to produce WFI rather than quantitative measurements of the final product. This is a problem because the standard process equipment will not meet NASA's mass requirements and may not function properly in the space environment. There is an additional complication because NASA potable water specifications do not match the EPA potable water specifications that are assumed to be the initial source water. Detailed specifications will have to be developed to 
ensure the medical water system and the final produced solutions meet the spirit of the regulations if not the specific process regulations.

Many potential technologies can be utilized to produce the purified water. Many of these technologies are commercially used to purify liquids in industry, or are being developed in advanced systems for potable water production. The USP currently states the "Water for Injection is water purified by distillation or by a purification process that is equivalent or superior to distillation in the removal of chemicals and microorganisms." To date, reverse osmosis is the only acceptable alternative to distillation within the USP WFI standards. The USP WFI standards were developed for production of continuous quantities of at least tens of liters per hour. NASA, on the other hand, requires a much smaller production rate and volume capability, so other production technologies may be preferred.

Maintaining sterility is more of a concern with occasional production, and the production system may be altered to include components that are utilized only for limited durations to prevent contamination. NASA could use technologies in a unique fashion to directly produce a solution while bypassing any storage of WFI. A future trade study will evaluate the potential technologies, incorporating the results of small breadboard studies, and recommend the type of system that should be developed for NASA's Exploration missions.

\section{Acknowledgments}

The authors gratefully acknowledge support from the NASA Exploration Medical Capabilities Program in the Exploration Systems Mission Directorate. John McQuillen of the Glenn Research Center provided valuable technical discussions and proofreading of this paper.

\section{References}

${ }^{1}$ NASA's Exploration Systems Architecture Study, NASA-TM-2005-214062, p. 217, 2005.

${ }^{2}$ http://sd.jsc.nasa.gov/PCDB/login.cfm

${ }^{3}$ Creager, G., "An Evaluation of IV Fluids Requirements for the Space Station Freedom Health Maintenance Facility Assuming a 10-Day Therapeutic Stay,” Krug Life Sciences, 1991.

${ }^{4}$ J. Ogle, M. Finley, and J. Kipp, “Space Station LVP Mixing System, Interim Report \#2,” Baxter Healthcare, June 1989.

${ }^{5}$ Niederhaus, C., Barlow, K., Griffin, D. Miller, F., "Medical Grade Water Generation For Intravenous Fluid Production on Exploration Missions," NASA-TM-XXXX (number not yet assigned; currently in review), 2006.

${ }^{6}$ Yowler, C. J. and Fratianne R. B., "Current status of burn resuscitation," Clin Plast Surg, Vol. 27, 2000, pp. 1-10.

${ }^{7}$ The Society of U.S. Naval Flight Surgeons, The United States Naval Flight Surgeon Handbook, 2nd edition, 1998.

${ }^{8}$ Lorenzo, M., Davis, J.W., Negin, S., Kaups, K., Parks, S., Brubaker, D., Tyroch, A. "Can Ringer's Lactate be used safely with blood transfusions?," Am J Surg, Vol. 175, 1998, pp. 308-309.

${ }^{9}$ Boldt J., Haisch G., Suttner S., Kumle B. \& Schellhase F. “Are Lactated Ringer's Solution and Normal Saline Solution Equal with Regard to Coagulation?," Anesth Analg, Vol. 94, 2002, pp. 378-384.

${ }^{10}$ Holliday, M. A. and Segar W. E., "The maintenance need for water in parenteral fluid therapy," Pediatrics; Vol. 19, 1957, pp. 823-832.

${ }^{11}$ United States Pharmacopeia ,National Formulary, currently USP 29-NF 24, 2006.

${ }^{12}$ System Specification for the International Space Station, NASA SSP 41000, 1996.

${ }^{13}$ Bagdigian, R., Cloud, Dale, and Bedard, J., "Oxygen Generation Systems Status of the Regenerative ECLSS Water Recovery," SAE 2006-01-2057, 2006.

${ }^{14}$ Niederhaus, C. E. and Miller, F. J. Intravenous Fluid Mixing in Normal, Partial, and Micro- Gravity: Down-selection of Mixing Methods, NASA TM-XXXX (report submitted, but number not yet assigned), 2006.

14 Joshi, J, "Human Support Technology Research to Human Support Technology Research to Enable Exploration," NASA/TM-2003-212598 Results of the Workshop on Two-Phase Flow, Fluid Stability and Dynamics: Issues in Power, Propulsion, and Advanced Life Support Systems p. 97-127,2003. 